\title{
Generation of reactive oxygen species by beta amyloid fibrils and oligomers involves different intra/extracellular pathways
}

Giovanna Cenini - Cristina Cecchi - Anna Pensalfini · Sara Anna Bonini - Giulia Ferrari-Toninelli ·

Gianfranco Liguri · Maurizio Memo - Daniela Uberti

Published online: 1 September 2009

(C) Springer-Verlag 2009

Erratum to: Amino Acids (2009)

DOI 10.1007/s00726-009-0319-7

The original version of this article unfortunately contained a mistake.

The presentation of the first author's name was incorrect.

The corrected presentation is given below.

Giovanna Cenini, Cristina Cecchi, Anna Pensalfini, Sara Anna Bonini, Giulia Ferrari-Toninelli, Gianfranco Liguri, Maurizio Memo and Daniela Uberti.

The online version of the original article can be found under doi:10.1007/s00726-009-0319-7.

G. Cenini - S. A. Bonini - G. Ferrari-Toninelli - M. Memo ·

D. Uberti $(\square)$

Department of Biomedical Sciences and Biotechnologies,

University of Brescia, Viale Europa 11, 25124 Brescia, Italy

e-mail: uberti@med.unibs.it

C. Cecchi - A. Pensalfini - G. Liguri

Department of Biochemical Sciences, University of Florence,

Florence, Italy 